\title{
Igreja Matriz de São Raimundo Nonato/PI: uma análise a partir da arqueologia da arquitetura
}

\author{
Ana Raquel Neves Maia* \\ Alencar de Miranda Amaral**
}

\begin{abstract}
MAIA, A.R.N.; AMARAL, A.M. Igreja Matriz de São Raimundo Nonato/PI: uma análise a partir da arqueologia da arquitetura. R. Museu Arq. Etn. 34: 72-86, 2020.
\end{abstract}

Resumo: Este trabalho estuda o edifício histórico da Igreja Matriz de São Raimundo Nonato/PI, pelo viés da arqueologia da arquitetura. Trata-se de uma edificação de grande valor histórico para a cidade e uma de suas construções mais antigas: foi erigida em 1876, data anterior à própria emancipação da cidade. O foco principal deste trabalho foi identificar, analisar e descrever as características arquitetônicas e construtivas presentes na estrutura externa da Igreja, ou seja, a fachada. A arqueologia da arquitetura e a arqueologia histórica nos deram o embasamento teórico e metodológico necessário para analisar essas características e, por meio dos apontamentos da bibliografia especializada, identificar comparativamente que ela se correlacionava aos modelos arquitetônicos vigentes no período colonial. Partindo desses pressupostos foi possível elencar 22 características arquitetônicas e construtivas coloniais na fachada da Igreja Matriz, além de corroborar sua adequação ao estilo arquitetônico denominado chã/chão.

Palavras-chave: Arqueologia da arquitetura; Igreja; Colonial.

\section{Introdução}

\footnotetext{
igreja matriz abordada se localiza na cidade de São Raimundo Nonato, sudeste do estado do Piauí. Segundo Silva, Rocha \& Melo (2015), boa parte das capitais nordestinas teve uma igreja como componente determinante na sua formação, ou seja, as igrejas auxiliaram na consolidação, surgimento e povoamento dessas localidades. Ocupando

* Graduada em Arqueologia e Preservação Patrimonial pela Universidade Federal do Vale do São Francisco (Univasf). Mestranda do Programa de Pós-Graduação em Arqueologia da Univasf, campus Serra da Capivara. <anaraquel164@hotmail.com>

** Docente da Universidade Federal do Vale do São Francisco (Univasf), campus Serra da Capivara. <alencar.univasf@gmail.com>
}

posição de destaque na expansão da malha urbana, essas igrejas geralmente se localizam e dão origem aos centros das cidades. A partir dessa colocação vemos que essa organização não ocorre somente em capitais, mas também nas cidades interioranas, como é o caso de São Raimundo Nonato. São Raimundo Nonato foi decretada freguesia eclesiástica em 1832; com seu posterior desenvolvimento, em 1850 foi elevado à categoria de vila; e, em 1912, transformou-se em cidade (Dias 2001). Voltando à questão da urbanização e expansão das construções a partir de um centro comum, "a igreja”, essa verificação é constatada a partir das edificações mais antigas da cidade, que em sua maioria se localizam no entorno da igreja. Essas casas, atualmente utilizadas para moradia 
e comércio, têm auferidas suas datas de construção que vão desde o início do século XIX até fins do século XX (Piauí 2012), ou seja, algumas destas são contemporâneas à igreja estudada. A construção da igreja teve início em 1874 e ela foi terminada e inaugurada em 1876 (Carvalho et al., 2016), portanto antes da emancipação política, que ocorreu em 1912. Segundo Cavalcante (2008), o seu idealizador foi o Frei Henrique José Cavalcante, responsável pela construção de igrejas e outras variadas obras em distintos estados como Bahia, Pernambuco, Ceará e Piauí.

A pesquisa teve o seguinte problema norteador: quais as técnicas e as características arquitetônicas predominantes na construção da Igreja Matriz de São Raimundo Nonato/PI? Esta edificação apresenta características singulares ou pode ser enquadrada em um modelo construtivo predominante no século XIX, ou seja, um determinado estilo arquitetônico vigente na época de sua edificação?

Correlacionar determinada construção a um estilo arquitetônico específico tem suas limitações (Brazon 2012; Pereira 2005), pois no caso brasileiro o que é verificado é a manutenção de formas de construir e características arquitetônicas além dos períodos estabelecidos, ou também a coexistência de várias características arquitetônicas, elencadas como pertencentes a um estilo ou outro. Apesar disso é inegável a possibilidade de identificar essas similaridades a partir da classificação dos elementos que compõe a edificação. Na apresentação dos resultados identificamos que a construção é muito similar à denominada arquitetura chã (que é em si um estilo colonial, considerado por alguns autores como abarcando construções com características maneiristas) (Rio de Janeiro, 2000), porém, como já dito, no Brasil os estilos não são bem delimitados. Temos ciência da variedade das arquiteturas coloniais; segundo a bibliografia especializada, o termo "colonial" corresponderia ao período que vai desde o descobrimento do Brasil em 1500 até a sua independência, em 1822. Porém utilizamos no sentido não o relacionando a uma data específica, mais a uma forma de construir e características arquitetônicas típicas desse período, mais precisamente a arquitetura implementada nos primórdios da colonização. A edificação estudada, mesmo se situando histórica e cronologicamente fora do período denominado pela bibliografia especializada como "colonial", apresenta características arquitetônicas semelhantes às relativas a esse período.

A busca centrou-se na identificação das características arquitetônicas presentes na estrutura e sua adequação à arquitetura colonial, com o intuito de verificar se a edificação seguia um padrão construtivo vigente na época ou se se tratava de um monumento de arquitetura singular; para isso foi estudada sua parte externa (fachada).

\section{Contextualização histórica}

A igreja estudada, além de matriz, também é catedral da Diocese de São Raimundo Nonato. E essa posição muda expressivamente sua significância com relação às demais, pois em uma diocese só existe uma única Catedral.

Como dito anteriormente, a Igreja Matriz de São Raimundo Nonato/PI foi edificada em 1876, e segundo Gomes (2015: 21) "a fundação da igreja em São Raimundo Nonato-PI teve iniciativa do Padre José Henrique Cavalcante, com contribuição de pessoas com certo poder aquisitivo, e com participação do povo em geral".

Segundo Aquino \& Santos (2014: 37), frei Henrique $^{1}$ foi:

1 "O Padre José Henrique Cavalcante natural de Saboeiro-CE que foi responsável pela construção de várias obras por onde passou incluindo igrejas, cemitérios, açudes" (Aquino \& Santos, 2014: 37). 
Igreja Matriz de São Raimundo Nonato/PI: uma análise a partir da arqueologia da arquitetura R. Museu Arq. Etn., 34: 72-86, 2020.

Ordenado em 1862 e foi enviado para a cidade de Missão Velha-CE, onde atuou de 1866 a 1867. Em 1870, ele deixa a paróquia de Missão Velha e se dedica a percorrer o sertão construindo igrejas e benfeitorias. A decisão de percorrer o sertão, frei Henrique atribuia ao chamado de Deus em beneficio dos povos, tendo percorrido o interior do Ceará, de Pernambuco, da Bahia e do Piaui. O trabalho de Frei Henrique Cavalcante teve papel decisivo para o desenvolvimento de algumas regiões, tendo contribuido para o desenvolvimento urbano de algumas áreas, realizando construções, para as quais ofrei mobilizava a população.

Segundo Almeida Neta \& Kestering (2013), antes da construção do novo templo da atual catedral, existia uma capelinha que havia sido construída em 1836. Ela foi destruída posteriormente com o início da construção, e em seu local foi implantado um "belíssimo" cruzeiro (Fig. 1). O cruzeiro foi destruído em 1964 pelo então prefeito da cidade Gaspar Dias Ferreira, sob o pretexto de urbanizar a praça.

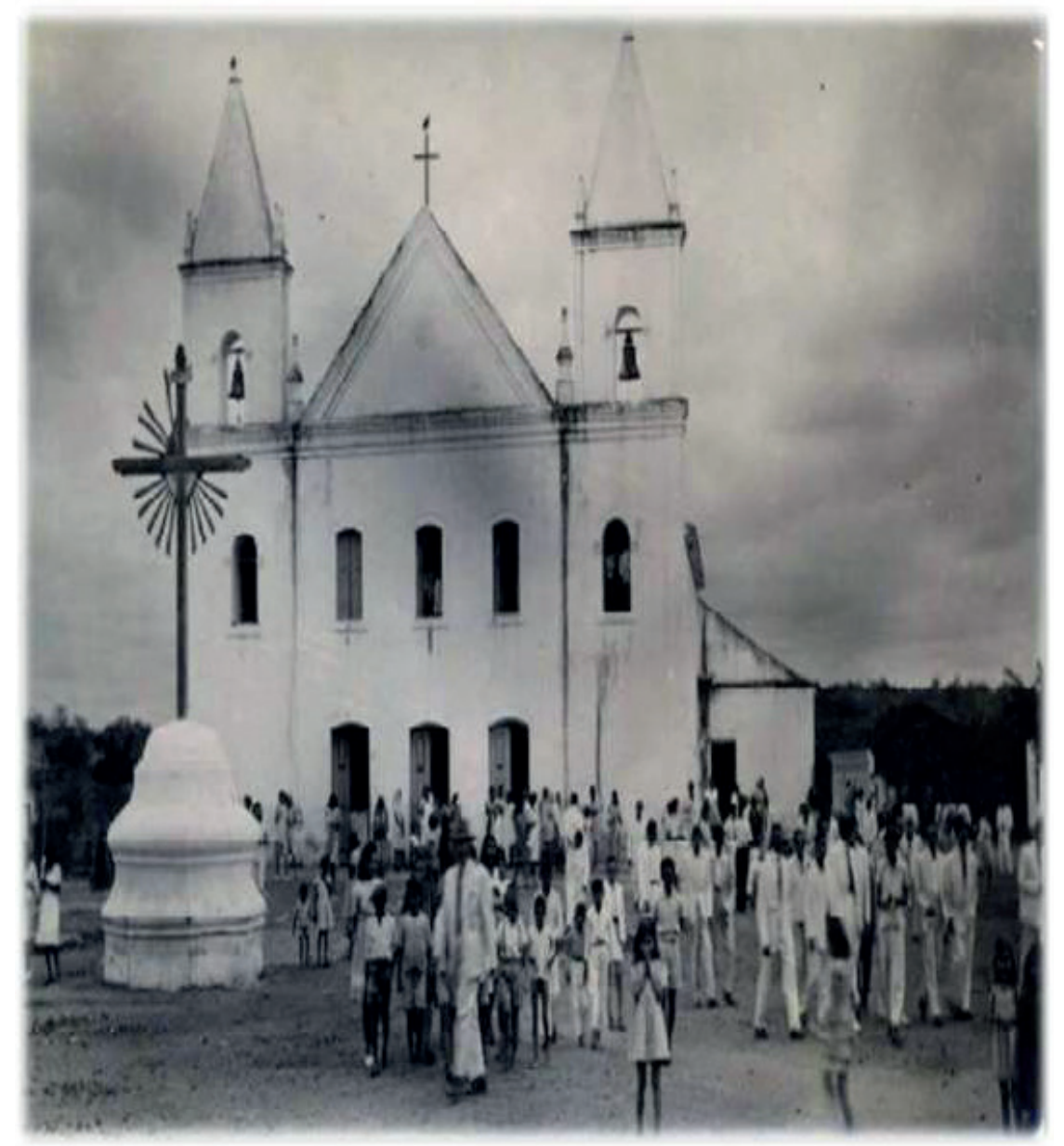

Fig. 1. Fotografia da Igreja Matriz de São Raimundo Nonato com a presença do cruzeiro a frente, Data da Foto: 19??. Fonte: Kestering (2013). 
Algumas fotos de igrejas antigas nos trazem indícios de um mesmo padrão arquitetônico ${ }^{2}$, e provavelmente construtivo, em várias

2 O qual estamos tentando desvelar, constatamos que elas possuem muitas similaridades mais não há estudos sobre sua filiação estilística de fato. No mínimo o que ocorre é a correlação a categoria colonial que é em si muito ampla, estudar a Igreja de São Raimundo Nonato e posteriormente compreender a correlação das características arquitetônicas nos traz indícios de um possível estilo que pode ter sido adotado também nas demais construções religiosas da região. localidades do interior nordestino. É o caso da Igreja Matriz de Petrolina (Fig. 2A), representada na foto pertencente ao acervo da Expedição Oswaldo Cruz, que passou pela região em 1912; a Igreja de São João do Piauí, também construída pelo Frei José Henrique Cavalcante, em 1875 (Fig. 2B); a de Remanso (Fig. 2C); e Pilão Arcado (Fig. 2D), na Bahia (estas últimas já destruídas, pois o local onde se localizam foi inundado para construção da barragem de Sobradinho).
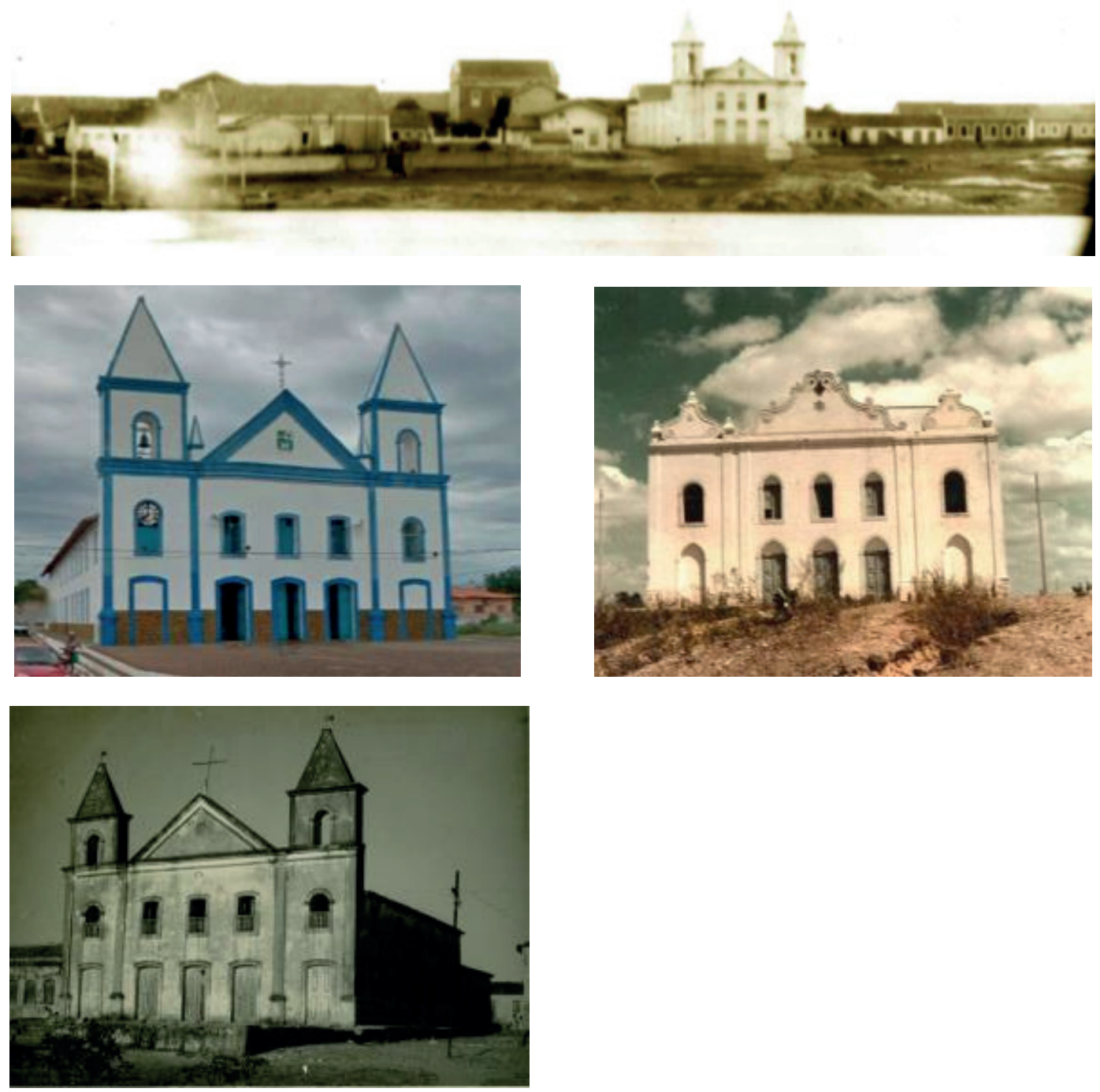

Fig. 2. Igreja Matriz de Petrolina/PE (A), São João do Piaui/PI (B), Remanso Velho/BA (C) e Pilão Arcado/BA (D). Fonte: Instituto Oswaldo Cruz (2019), Google Street View, Pires (2008) e IBGE (2017). 


\section{Fundamentação teórica}

A arqueologia da arquitetura "pode ser definida de maneira geral como uma corrente de pesquisa que abarca todos aqueles trabalhos direcionados ao estudo da arquitetura de um ponto de vista arqueológico, ou seja, centrados na análise de sua materialidade” (Steadman 1996 apud Zarankin 2001: 52). "As construções são vistas como elementos ativos, produtos culturais que interatuam de forma dinâmica com o homem" (King 1980 apud Zarankin 2001: 51).

Desenvolvemos nossas análises partindo do pressuposto de que a edificação se constitui como um superartefato, conceito proposto por Rosana Najjar (2011: 1), que propõe que os edifícios sejam estudados como sendo o próprio artefato em si mesmo. E como o objeto de estudo da arqueologia não é a cultura material em si, mas o homem que a manipulou e a produziu, uma construção deve ser encarada como qualquer artefato passível de estudo arqueológico, assim como um fragmento de cerâmica, uma peça lítica etc.

Segundo Najjar (2002: 9-10), um dos objetivos comuns entre as áreas que estudam as edificações é a "necessidade de contar, o mais completamente possível, a história do bem, ou seja, as possíveis alterações físicas e suas respectivas (ou não) mudanças de uso". Assim, as edificações devem ser estudadas como se fossem, elas próprias, um superobjeto, um superartefato, e não meramente o lugar onde estão localizados os objetos. Desta maneira, a própria edificação ganha "vida".

Uma edificação é um superartefato, construido pelo homem, que, necessariamente, está inserido num dado tempo e espaço e, deste modo, carregado de valores e simbolismos.

As edificações são, assim, produto e produtoras de relações sociais, as quais pretendemos desvelar para melhor conhecermos o bem que temos o dever de preservar (Najjar 2002: 11).

Os trabalhos realizados a partir dessa premissa são efetivos "resgaste[s] da história do bem e da sociedade que o construiu" (Najjar 2002: 11).
A partir desses pressupostos teóricos, salientamos que apesar de nossas análises se focarem nos elementos formais e técnicos que compõe o edifício da Igreja Matriz, estamos cientes que ele está associado e representa o contexto social no qual se encontrava, assim como a cultura material expressa na forma de qualquer artefato arqueológico. Portanto ao estudar uma edificação do ponto de vista da cultura material (superartefato), estamos estudando nada mais do que o homem e a sociedade que o produziu.

\section{Características da arquitetura colonial e} arquitetura chã

\section{Ao definir a arquitetura como} "construção concebida com a intenção de ordenar plasticamente o espaço, em função de uma determinada época, de um determinado meio, de uma determinada técnica e de um determinado programa” (Costa, 1952:5-6), Lúcio Costa (1952: 5; grifo do autor) ressalta que todo projeto arquitetônico "depende ainda, necessariamente, da época da sua ocorrência, do meio físico e social a que pertence, da técnica decorrente dos materiais empregados e, finalmente, dos objetivos visados e dos recursos financeiros disponíveis para a realização da obra, ou seja, do programa proposto". Assim o autor afirma que:

Quando se estuda qualquer obra de arquitetura, importa ter primeiro em vista, além das imposições do meio físico e social, consideradas no seu sentido mais amplo, o "programa", isto é, quais as finalidades dela e as necessidades de natureza funcional a satisfazer; em seguida, a "técnica", quer dizer, os materiais e o sistema de construção adotados; depois, o "partido", ou seja, de que maneira, com a utilização desta técnica, foram traduzidas, em termos de arquitetura, as determinações daquele programa; finalmente, a "comodulação" e a "modenatura", entendendo-se por isto as qualidades plásticas do monumento (Costa 2010: 130). 
Deste modo, nessa etapa da pesquisa nos dedicamos à análise da bibliografia especializada com o objetivo de conhecer os padrões construtivos e arquitetônicos do período colonial relacionados, mais precisamente, à arquitetura religiosa. Portanto, através do estudo de igrejas de outras regiões, buscamos o embasamento para identificação e análise das características arquitetônicas e construtivas da Igreja Matriz de São Raimundo Nonato.

Neste sentido merece destaque a análise sobre "O caráter da arquitetura colonial do Nordeste” realizada por Robert Smith em 1940, na qual ele ressalta a importância dos modelos metropolitanos na ereção das igrejas nordestinas. Segundo Smith (2012: 78), nota-se tanto uma tendência "a imitar o estilo barroco das igrejas rurais das províncias portuguesas" quanto empréstimos de "pormenores de construção e decoração" da "arquitetura oficial" da corte de Lisboa e dos outros centros lusitanos ${ }^{3}$.

Do mesmo modo, apesar de reconhecer as "diversas tradições que distinguem a arquitetura na Espanha e em Portugal”, Bury (2006: 127) argumenta que as igrejas construídas nas colônias americanas ao sul do Equador, geralmente seguiam "os estilos da península Ibérica", mesmo quando diante das particularidades locais como a disponibilidade dos materiais construtivos. Segundo Bury (2006: 127),

apesar destas e de outras diferenças, nota-se uma certa uniformidade subjacente a todo o conjunto de obras de arquitetura religiosa nas colônias espanholas e portuguesas, graças a um traço básico comum, a utilização universal e conservadora de plantas baixas retangulares.

3 "Durante todo o século XVIII permaneceu no Nordeste a tendência de imitar a arquitetura oficial portuguesa. $\mathrm{O}$ melhor exemplo dessa tradição está, sem dúvida, na Igreja da Conceição da Praia, em Salvador, cuja reforma se iniciou em 1735-1736 e cuja pedraria se importou diretamente da metrópole. A disposição da sua fachada, cerrada entre duas torres salientes, em um edifício em forma de palácio quadrado, compreendendo as sacristias, escadarias monumentais e os apartamentos de serviço subsidiários, lembra o edifício do vasto convento de Mafra, verdadeira obra-prima da arquitetura joanina” (Smith 2012: 79).
Assim, o autor destaca que:

Os dados disponiveis indicam que a grande maioria das igrejas construídas nas possessões portuguesas de além-mar, entre o final do século XVI e o início do XVIII, pelo menos, obedecia a um traçado padrão, quase estereotipado. Seja na América, na África ou na Ásia, encontramos a mesma estrutura elementar, semelhante à de um galpão, com uma única porta de entrada, duas janelas alongadas dispostas de ambos os lados acima e um óculo na empena. Essa composição dos vãos em diagonal pode ser relacionada, tanto em Portugal como na Itália, a precedentes medievais, as janelas laterais correspondendo originalmente a naves laterais (Bury 2006: 131).

A predominância das plantas quadrangulares também é destacada por Smith em seu clássico ensaio de 1955 sobre arquitetura colonial, no qual o autor propõe uma periodização para as construções religiosas do país, que como apontado por Lima Toledo (2012: 26), se torna referência para os posteriores estudos sobre a arquitetura religiosa do Brasil Colônia.

Segundo Smith (2012: 263), é possivel observar no decorrer da colonização três períodos com características arquitetônicas próprias. O primeiro, é chamado de "missionário" e vai de 1549 a 1655; sendo inicialmente caracterizado por edificações modestas de madeira e taipa, conhecidas como "igrejas de palha", essas foram gradativamente substituídas por construções de "pedra e cal", com coberturas de telhas fabricadas in loco. As igrejas deste período compunham-se, via de regra, de uma só nave, retangular, com um retângulo menor em projeção formando a capela-mor, e um cômodo lateral que seria a sacristia. $\mathrm{O}$ segundo período compreende o intervalo entre 1655 e 1760, sendo designado pelo autor como "monumental", refletindo a opulência e riqueza gerada, inicialmente, pela economia açucareira. Do ponto de vista arquitetônico, a principal característica das igrejas desse período é a presença de uma grande nave central retangular, conjugada com capelas laterais intercomunicantes, completando 
o conjunto com uma nave menor, também retangular, servindo de capela-mor. Por fim, no terceiro período, entre 1760 e 1820, designado como "mundano", as igrejas não apresentariam a mesma grandiosidade presente no período anterior, sendo os templos majoritariamente compostos por uma nave retangular maior, com nichos laterais com altares embutidos, em vez de capelas, e uma nave retangular menor, que seria a capela-mor.

Já Lúcio Costa, ao analisar em 1941 a "Arquitetura dos jesuítas no Brasil", aponta a existência de quatro tipos diferentes de plantas. Inicialmente teríamos as "singelas" e "rudimentares" capelas do começo da atuação inaciana, nas quais "a capela-mor e a nave constituem um mesmo corpo de construção dividido convencionalmente em duas partes por um arco cruzeiro" (Costa 2010: 142). O segundo tipo seria composto por "igrejas onde aparecem perfeitamente diferenciadas a nave e a capelamor propriamente dita, de largura e pé-direito menores, partido claro e franco de composição" (Costa 2010: 142). O terceiro tipo reúne igrejas que, além dos três altares usuais do modelo, têm como "particularidade, porém, de se criarem, também para os colaterais, pequenas capelas apropriadas, de maior ou menor profundidade, como no caso da igreja de Olinda, onde tais capelas formam conjunto com a capela-mor (Costa 2010: 142). Por fim, o último tipo englobaria as "igrejas maiores seiscentistas", que

em vez dos três altares - caso mais geral nas igrejas do tipo anterior - contam-se aqui numerosos altares dispostos em capelas laterais, sendo que as duas mais próximas da capelamor faziam-se quase sempre mais largas e mais altas, quando não também mais profundas, com aquele mesmo objetivo de marcar, em planta, o cruzeiro (Costa 2010: 143).

O autor também descreveu o padrão "jesuítico" de frontispício, no qual:

[...] as volutas da empena desenvolvemse livremente, o frontão que remata o corpo central ficou reduzido a proporções exíguas e as torres, vistas de frente, mal cabem na fachada, parecendo mais sineiras que propriamente torres, a ponto de o conjunto reproduzir, feita abstração dos pormenores e da escala monumental, a silhueta das pequenas capelas de duas sineiras, comuns tanto na metrópole como na colônia (Costa 2010: 143).

Sendo que se encontram frontispícios tanto de uma porta só, como conjuntos formados por cinco vãos, com portais que poderiam ser de mármore de Lioz, "granito do país" ou de outras matérias-primas locais (Costa 2010: 151).

Por sua vez, Bury chama atenção para a recorrência da orientação diagonal das fachadas das igrejas construídas nas colônias lusitanas ao redor do mundo. Segundo o autor,

\section{[...] a fachada de composição diagonal era} um traço provinciano, e como tal teve seu uso generalizado nas colônias portuguesas. Por outro lado, nas capitais coloniais, como Velha Goa e Salvador, as fachadas das igrejas apresentavam uma disposição regular de vãos em carreiras superpostas, seguindo a moda mais sofisticada da metrópole. Da mesma forma, o uso de torres laterais nas fachadas, que se tornara uma prática quase invariável nas cidades principais das colônias durante o século XVIII, vai ficando cada vez mais raro nas povoações mais remotas da periferia (Bury 2006: 132).

Smith (2012: 283) também chama atenção para o fato de a fachada principal ser a única parte externa da igreja colonial que se ornamentava. Os lados e o fundo dos edifícios não apresentavam adorno de espécie alguma, sendo simplesmente rebocados. As portas laterais eram deixadas sem decoração, com raras exceções, como as da antiga catedral de Salvador; e o único relevo existente era dado pelos ocasionais ângulos das pilastras.

Ao analisar as fachadas das igrejas coloniais da Bahia, Smith (2012: 269) assegura que é possivel perceber certa uniformidade. Todavia, o autor destaca que é possível identificar idiossincrasias que ocorreram ao longo do tempo, e que integram as características dos três períodos estabelecidos pelo autor, como citamos anteriormente. Assim, Smith aponta que apesar 
de as igrejas missionárias, de 1549 a 1655 , não contarem mais com suas fachadas originais, é possível reconhecer seu padrão através da documentação histórica. Deste modo, o autor afirma que nesse período:

O desenho da fachada é de extrema simplicidade, emoldurada por pilastras dóricas arrematada por um frontão acentuadamente pontudo. A portada única e uma modesta moldura de pedra, encimada por uma verga plana que se projeta levemente sobre um friso estreito. Acima, duas janelas quadradas e entre elas um nicho arqueado, havendo no frontão uma abertura circular com o mesmo tipo de moldura de austera simplicidade. A esquerda, uma pequena torre com um campanário baixo (Smith 2012: 269).

Já entre 1655 e 1760, período monumental, as fachadas tornam-se mais amplas, sendo predominante os traços essenciais da "frontaria jesuíta”, que segundo Smith (2012: 270) caracteriza-se pela

divisão em duas ordens de colossais pilastras dóricas; aparição de torres gêmeas na fachada; introdução de um frontão central emoldurado por volutas recurvadas a maneira barroca; uso de três portas de entrada em grupo unido, com molduras elaboradamente esculturadas de motivos arquitetônicos.

Além disso, o autor destaca que outro elemento marcante deste período é "a terminação piramidal que, na maior parte das igrejas baianas do estilo monumental, substituiu a forma semiesférica anterior" (Smith 2012: 271-273).

Por fim, sobre o período mundano, Smith (2012: 280-281) observa que

As frontarias das igrejas construidas entre 1765 e 1820, se bem que ainda conservem o antigo arcabouço de pilastras simples que se manteve imutável durante todo o período colonial, passam a apresentar uma nova maneira de usar as linhas ondulantes e chamejantes, menos extravagantes que nas igrejas mineiras e pernambucanas do mesmo tempo, porém sensivelmente mais dinâmica do que em todas as ornamentações precedentes, na Bahia. Esse novo tipo de composição começou a aparecer nos zimbórios das torres que adotaram uma grande variedade de formas plásticas, frequentemente acentuadas por alongadas e flamejantes urnas de pedra nos ângulos. [...] Similarmente, a forma dos frontões alterouse no sentido de um alongamento pronunciado [...]. As antigas volutas comprimiram-se nos lados em moldes mais estreitos, e a superfície central e frequentemente ocupada por uma janela de rebuscada forma rococó, emoldurada por um cinzelado complexo e delicado, sendo o exemplo mais elegante encontrado na Igreja de N. Sra. do Pilar. As molduras das portas e das janelas alongam-se da mesma maneira, rematadas por vergas de motivos paralelos caprichosamente ondulados. Quando estas, ocasionalmente, eram colocadas em posições contiguas, como nas igrejas de N. Sra. da Saúde e Glória e de Conceição do Boqueirão, o efeito obtido é o de um intenso e continuado movimento de adejo. O ornamento consiste em urnas de flores, de fitas e alegres guirlandas, como nas portadas da Ordem Terceira de S. Domingos e de Conceição do Boqueirão, de espirito inteiramente mundano, que oferece o nome apropriado ao estilo do periodo.

Nesta breve incursão pela bibliografia especializada, podemos observar que a análise da arquitetura religiosa do período colonial levou historiadores da arte e arquitetos a identificarem e registrarem diversos elementos destas construções. A partir destes estudos, segundo Pinheiro (2013) também é possível identificar os três centros principais de irradiação da arquitetura religiosa brasileira: Bahia, Rio de Janeiro e Minas Gerais.

Isto posto, seja pela proximidade geográfica ou pela ativa participação baiana na colonização do sudeste do Piauí, podemos observar uma significativa proximidade entre os padrões arquitetônicos de diversas igrejas baianas com a Matriz/Catedral de São Raimundo Nonato.

Para esse panorama de comparação, além das obras anteriormente citadas, merece destaque o trabalho de Mayer (2003), uma análise de aspectos 
Igreja Matriz de São Raimundo Nonato/PI: uma análise a partir da arqueologia da arquitetura R. Museu Arq. Etn., 34: 72-86, 2020.

gerais da arquitetura religiosa colonial da Bahia que pode ser extrapolada para nossa região. Segundo Mayer (2003), as igrejas da Bahia até o século XVII se caracterizavam pela semelhança com o estilo que foi denominado por George Kubler de plain architecture, termo traduzido para "arquitetura chã". No Brasil, este tipo de modelo arquitetônico, caracterizado pela simplicidade e falta de ornamentação, estaria associada à atuação de construtores jesuitas e militares ${ }^{4}$.

Segundo Loewen (2011: 66):

O termo "estilo-chão" tem sido usado pelos historiadores de arte portugueses para descrever sua arquitetura religiosa a partir de 1570; a expressão foi cunhada pelo americano George Kubler, em sua obra de 1972, para uma série de grandes edifícios, em sua maioria igrejas e conventos, construidos em Portugal entre o segundo quartel do século 16 - quando do abandono da decoração manuelina - e o início do século 18, com o regresso à ornamentação exuberante. $\mathrm{O}$ autor procura demonstrar que a arquitetura "chã" portuguesa, ainda que motivada tantos por fatores econômicos quanto por uma mudança no "gosto" das cortes reais que se sucederam, difere significativamente do "estilo desornamentado" espanhol e antecede o mesmo. Em seu entendimento, tal estilo de Espanha foi, em grande medida, influenciado pelas fórmulas acadêmicas de Vignola, ainda que os edifícios realizados não possam ser ditos italianizantes. Em Portugal, ao contrário, a arquitetura-chã se aproximava mais de uma arquitetura vernácula que dos grandes autores do passado.

Para Teles (2014: 66) as igrejas enquadradas nesse padrão, mesmo "diferentes entre si, têm como característica comum a sobriedade da composição e o despojamento decorativo de

4 Os jesuítas estiveram a par dessas questões, adaptando a arquitetura de suas capelas, igrejas, residências e colégios aos condicionantes impostos pelo meio, à técnica disponível, à mão de obra utilizada e aos modelos arquitetônicos produzidos nos principais centros de referência colonial (Salvador da Bahia, Olinda, Recife e São Luís) e da Europa. Como Frisado por Wittkower, "os jesuítas, longe de ignorar os sentimentos e tradições populares, normalmente se adequam aos costumes locais na arte e na arquitetura" (Arraes 2014: 92). suas fachadas e interiores”. Já Senos (2012: 9) argumenta que esse tipo de construção possuía valores de simplicidade, austeridade, depuramento, numa palavra, chãos. Sua adaptabilidade e economia possibilitou ser implantada nos mais variados locais.

Assim, as construções feitas nos moldes da arquitetura chã eram de fácil execução e predominava a funcionalidade demonstrada pelo despojamento decorativo; ou seja, a decoração era praticamente deixada de lado e o edifício reduzido a cumprir somente sua função.

Como destacado por Kubler, as igrejas deste estilo eram caracterizadas por sua:

arquitetura eclesiástica de leitura simples, desprovida de elementos decorativos, e que foi classificada como "chã". Era uma arquitetura recorrente na metrópole, destacando-se através de edifícios guarnecidos de frontão triangular arrematando fachada provida de portada em pedra com duas aberturas simetricamente dispostas na porção superior (Kubler 2005 apud Cavalcanti Filho 2013: 2).

Outras características típicas da arquitetura chã podem ser observadas na obra de Cavalcanti Filho (2013), que desenvolveu uma análise de painéis (azulejos) com imagens de igrejas desse período. A partir deste levantamento o autor descreve os elementos que são recorrentes e/ou caracterizadores deste estilo arquitetônico: "igreja com frontão clássico, óculo, cunhais e portada centralizada [...], são destacados elementos de morfologia clássica como arcos plenos e cornijas em edifícios civis"; "igreja singela, com cobertura em duas águas, implantada em terreno elevado, e dotada de cunhais, óculo e portada clássica em cantaria"; "fachada simples, com frontão encimado a cornija e disposição de duas aberturas para o coro alto". Segundo o autor, a "iconografia da época demostra que era um modelo geral para qualquer edifício religioso" (Cavalcanti Filho 2013: 6). "As imagens dos referidos monumentos denunciam a natureza chã de sua arquitetura, onde a erudição estampada nos frontões clássicos, nas pilastras e nos entablamentos definia a leitura geral 
dos edifícios"; "O frontão clássico constituiria um dos seus principais indicadores formais, sem contar a cantaria dos cunhais, da portada única e do óculo que compunham a fachada” (Cavalcanti Filho 2013: 7-9).

Assim, tendo em consideração os direcionamentos apresentados referentes às arquiteturas colonial e chã, buscamos identificar quais destas características se encontravam na Igreja Matriz de São Raimundo Nonato/PI. arquitetônicas; registros fotográficos da estrutura e suas características, detalhes etc. Foi feita a esquematização por meio de um programa de edição de imagens (Inkscape) de algumas feições arquitetônicas como forma de melhor evidenciar seus detalhes, facilitando assim a análise de seus particulares arquitetônicos. Posteriormente, foi feita a identificação de quais as características coloniais apresentadas na bibliografia especializadas puderam ser verificadas na fachada.

\section{Resultados}

Por meio das leituras conseguimos definir as características gerais que construções religiosas coloniais/chã apresentam. Na análise da estrutura externa da Matriz destacamos quais desses elementos coloniais aparecem na fachada da Igreja Matriz de São Raimundo Nonato/PI (Fig. 3).

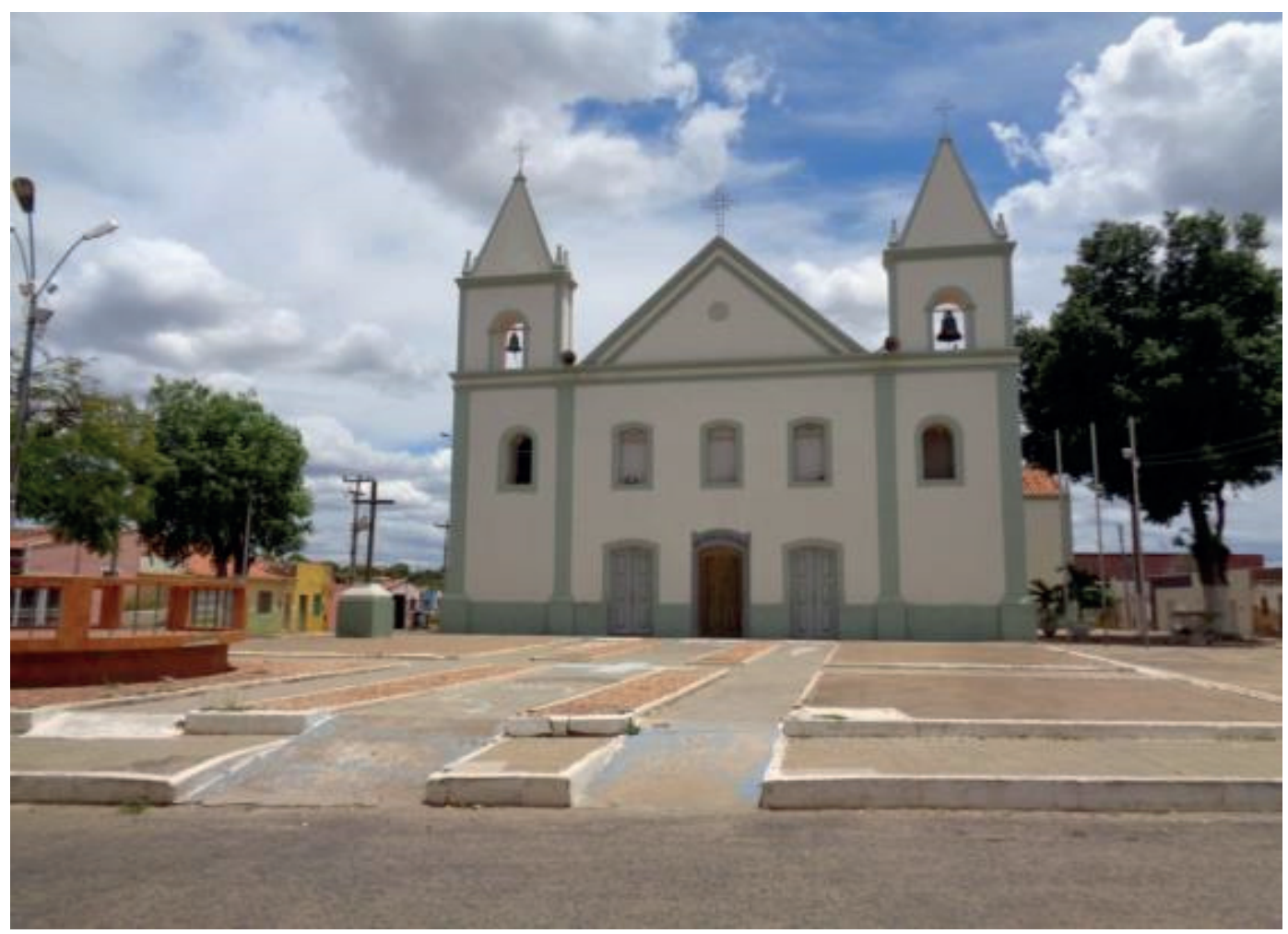

Fig. 3. Igreja Matriz de São Raimundo Nonato/PI atualmente.

Fonte: Ana Raquel, 24/01/2018. 
Como discutido anteriormente, as construções coloniais pertencentes ao maneirismo e que seguiam padrões do estilo chã, possuíam caráter sóbrio e austero se comparado a outras construções. As igrejas desse estilo eram construções "simples", não havendo uso de elementos curvos, o que garantiu certa sobriedade às fachadas. É o que vemos na Igreja Matriz de São Raimundo Nonato/PI, na qual podemos verificar que a fachada é composta basicamente por elementos em ângulos retos com o uso de quadrados e retângulos que formam o corpo, e sem o uso de decorações. Mais aspectos típicos do estilo colonial presentes na fachada do edifício são: frontão triangular; sineiras com coroamento piramidal; plano da fachada com duas torres sineiras; a fachada possui tramos e uma faixa horizontal marcada pela presença de pilastras e cornija; portada central de maior destaque com duas colaterais, superiormente possuindo uma linha de janelas; as torres coroadas com coruchéus, entre outros.

Todos esses elementos arquitetônicos foram analisados de forma mais ampla no trabalho monográfico e apresentado seu conceito de forma clara e didática, possibilitando fácil entendimento. Abaixo apresentaremos as características arquitetônicas e construtivas identificadas na fachada da Igreja Matriz de São Raimundo Nonato/PI.

A fachada principal possui um frontão ${ }^{5}$ retilíneo que é denominado frontão triangular ou piramidal, existem variadas tipologias de frontão e esse é um dos mais clássicos. É um elemento típico de construções coloniais que foi muito utilizado em fachadas de antigas igrejas. O frontão tem como elementos componentes a cimalha (base horizontal), empenas (lados inclinados) e tímpano (superfície central limitada pelas outras duas partes).

5 "Frontão é um elemento de coroamento da fachada geralmente triangular ou em arco de círculo, situado na parte superior do edifício ou em parte da edificação ou sobre portais, portadas ou portões. Originalmente tinha como função arrematar externamente os telhados de duas águas, decorrendo daí sua forma triangular. No decorrer do tempo tornou-se um elemento essencialmente decorativo" (Albernaz \& Lima 1998a: 276).
As cruzes localizadas no topo do frontão e das torres sineiras recebem o nome de grimpa ${ }^{6}$, elementos feitos em estrutura metálica. Elas se diferenciam em tipologia, apesar de ambas serem em formato de "cruz"? A cruz do topo do frontão em uma tipologia que se assemelha à cruz da Trindade e à cruz Trevo ${ }^{8}$. E as cruzes das torres sineiras possuem similaridade com a denominada cruz de Santiago?.

No centro do Frontão existe um ornato que é denominado medalhão de formato circular e que emoldura a data da construção do templo (1876).

A configuração da fachada com duas torres sineiras no mesmo plano da composição central configura-se uma típica fachada colonial. As duas torres sineiras/campanários são arrematadas por um coroamento piramidal ou acabamento piramidal que recebe o nome de flecha.

Sob as torres sineiras ao lado das flechas (coroamento piramidal/triangular) existe outro arremate ornamental que recebe o nome de coruchéus ${ }^{10}$. Existe um conjunto de quatro estruturas, de coruchéus contornando a flecha, em cada torre sineira. A tipologia dos coruchéus é piramidal.

A parte inferior da fachada é composta por três faixas verticais que recebem o nome de tramos. Tramo se configura como o espaço

6 Elemento ornamental metálico usado no alto das torres de edifícios, principalmente igrejas, podendo assumir diversas formas, muitas vezes simbólicas (Albernaz \& Lima 1998a: 298).

7 "Elemento ou traçado formado em geral por dois braços que se encontram em ângulo reto [...]. Apresenta formas variadas que, nos elementos, comumente expressam o símbolo representado" (Albernaz \& Lima 1998a: 191).

8 A cruz da Trindade possui remates de três círculos interseccionados. A cruz Trevo possui um desenho parecido com um trevo, que lembra a Santíssima Trindade (Cruz..., 2018).

9 Uma insígnia da ordem de São Tiago, fundada em 1160 para defender os peregrinos que se dirigiam ao santo sepulcro, do apóstolo São Tiago de Compostela (Cruz..., 2018).

10 "Arremate ornamentado no coroamento do edifício, pode ser de forma cônica, piramidal ou octogonal. Foi muito utilizado em edificações antigas providas de torres ou frontões, sobretudo igrejas. É também chamado de pináculo" (Albernaz \& Lima 1998a: 188). 
entre dois elementos arquitetônicos verticais, que no caso da igreja estudada são os espaços delimitados pelos cunhais ${ }^{11}$ nas extremidades e centralmente pelas pilastras ${ }^{12}$.

A distribuição de portas e janelas na fachada se organiza da seguinte forma: a fachada possui uma linha de cinco janelas - três centrais e uma em cada tramo lateral -, uma portada central - que recebe essa denominação por possuir maior destaque com relação às demais com duas portas colaterais.

Na parte inferior da fachada um elemento diferenciado se sobressai, delimitando uma linha na fachada, este é o embasamento ${ }^{13}$.

Os arcos das janelas e portas também foram analisados e classificados, identificando-se duas tipologias, uma delas com variação: arco abatido $^{14}$, arco pleno ${ }^{15}$ (com ou sem imposta ${ }^{16}$ ).

11 "Cunhal é a faixa vertical saliente nas extremidades de paredes ou muros externos do edifício. Servem de proteção a quina do edifício ou de ornamentação da fachada” (Albernaz \& Lima 1998a: 193).

12 "Pilastra é um elemento decorativo com a forma de um pilar. Utilizado em fachadas dividindo-as em planos verticais. Em construções antigas é usualmente dividida em partes: base, fuste e capitel" (Albernaz \& Lima 1998b: 470).

13 Parte inferior da construção. Situado no nível do chão, formando uma base, podendo possuir algum elemento de vedação. Podendo constituir uma base para cunhal, coluna ou pilar, pode se apresentar liso ou emoldurado. Além de possuir por vezes função de proteção da parte inferior desses elementos - feito de material resistente, como pedra -, serviria também em construções antigas para distribuir o peso do edifício em superfície maior (Albernaz \& Lima 1998a: 211).

14 Arco formado por círculos de raios diferentes entre si, sendo sua flecha menor que a metade da distância entre seus pontos de origem. Muito usado em vãos de esquadrias de construções influenciadas pelo romantismo em finais do século XIX (Albernaz \& Lima 1998a: 46).

15 Arco em forma de semicircunferência foi utilizado na arquitetura brasileira em vãos de portas e janelas a partir do século XIX (Albernaz \& Lima 1998a: 50).

16 Ornato com forma de consolo, que serve como moldura (Albernaz \& Lima 1998a: 313).
O frontão é adornado por um elemento que recebe o nome de cercadura ${ }^{17}$; ele também é encontrado nas portas e janelas, mas recebe uma denominação diferenciada, guarnição.

Sobre o retângulo componente da fachada e das torres sineiras existem os elementos cornija e cimalha. A cornija é composta por cimalha, lacrimal e sorto. Ela é constituída como uma moldura ou conjunto destas salientes, que servem de arremate superior a elementos arquitetônicos ou ao edifício. Quando se localiza no alto ou no meio da fachada, tem a função principal de desviar das paredes externas as águas pluviais que descem pelo telhado (Albernaz \& Lima 1998a: 183).

Todos os elementos arquitetônicos identificados, analisados e classificados na fachada resultaram no seguinte esquema (Tabela 1, Fig. 4), que aponta todos os elementos identificados (22).

\begin{tabular}{cccc}
\hline No & Elemento & No & Elemento \\
\hline 1 & Frontão & 12 & Base (Pilastra) \\
2 & Empena (Frontão) & 13 & Fuste (Pilastra) \\
3 & Tímpano (Frontão) & 14 & Capitel (Pilastra) \\
4 & Grimpa & 15 & Embasamento \\
5 & Medalhão & 16 & Arco abatido \\
6 & Campanário & 17 & arco pleno \\
7 & Flecha & 18 & Imposta \\
8 & Coruchéus & 19 & Cercadura \\
9 & Tramos & 20 & Guarnição \\
10 & Cunhal & 21 & Cornija \\
11 & Pilastra & 22 & Cimalha \\
\hline
\end{tabular}

Tabela 1: Elementos arquitetônicos e construtivos identificados na fachada da Igreja Matriz de São Raimundo Nonato/PI.

17 "Qualquer tipo de moldura ou arremate que contorne a peça ou um elemento construtivo" (Albernaz \& Lima 1998a: 139). 


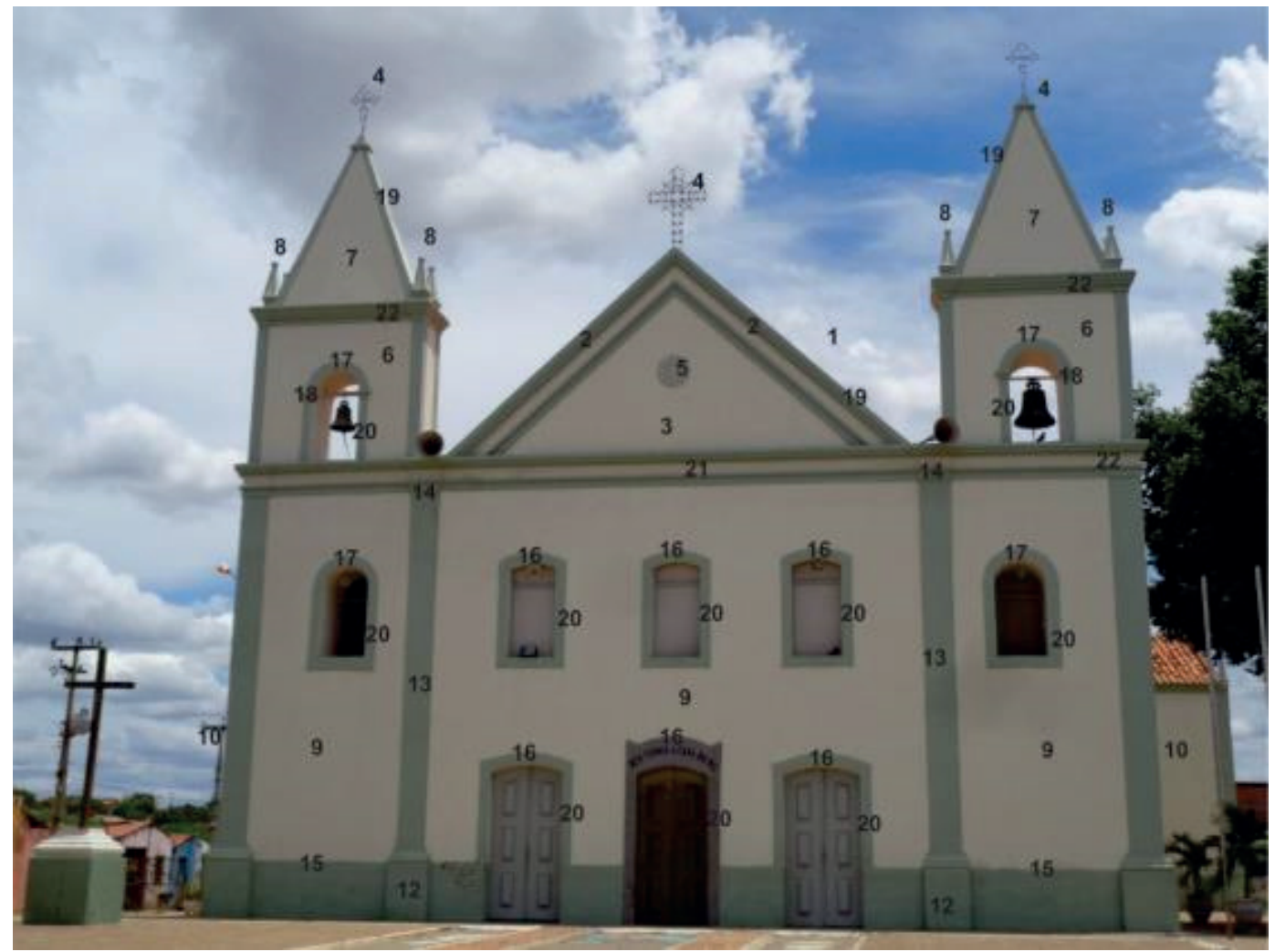

Fig. 4. Elementos arquitetônicos identificados na fachada da Igreja Matriz de São Raimundo Nonato/PI.

\section{Considerações finais}

As análises permitiram confirmar que sim, a Igreja Matriz de São Raimundo Nonato/PI possui uma similaridade muito grande com características coloniais, ou seja, elementos arquitetônicos de estilo colonial que formam a sua fachada. A igreja não é uma construção singular, mas sim faz parte de um conjunto/padrão maior que foi executado em variados locais. Não somente a edificação possui uma fachada com características coloniais como pode ser enquadrada no estilo denominado arquitetura chã, com o qual possui muitas similaridades.

Por meio de nossas análises foi possível identificar a presença de 22 características arquitetônicas na fachada da Igreja Matriz de São Raimundo Nonato/PI. A análise externa foi o foco desse primeiro momento da pesquisa; sua análise interna juntamente com a análise de outras igrejas da região serão o foco da pesquisa que será desenvolvida no âmbito do programa de mestrado da Universidade Federal do Vale do Vale do São Francisco.

MAIA, A.R.N.; AMARAL, A.M. Main Church of São Raimundo Nonato/PI: an analysis from the archeology of architecture. R. Museu Arq. Etn. 34: 72-86, 2020.

Abstract: This paper follows Archeology of Architecture to analyze the historical building of the Main Church of São Raimundo Nonato/PI, which has great historical value to the city and is one of its oldest buildings, built in 1876 before the political emancipation of the city. The architectural and 
constructive features present in the external structure of the church, the façade, were identified and described. Archeology of Architecture and Historical Archeology served as theoretical frameworks to verify these characteristics and to comparatively identify the correlation between this building with architectural models from the Brazilian colonial period by utilizing notes of the specialized literature. A total of 22 colonial architectural and construction features were found for the façade of the main church, corroborating its suitability for the architectural style called Chã/chão.

Keywords: Archeology of architecture; Church; Brazilian colonial period.

\section{Referências bibliográficas}

Albernaz, M.P.; Lima, C.M. 1998a. Dicionário Ilustrado de Arquitetura. Volume I-A a I. Proeditores, São Paulo.

Albernaz, M.P.; Lima, C.M. 1998b. Dicionário Ilustrado de Arquitetura. Volume II-J a Z. Proeditores, São Paulo.

Almeida Neta, M.F.; Kestering, C. 2013. Os rituais do morro do cruzeiro: atributos da identidade Sanraimundense. In: Kestering, C. (Org.). Anais Escavando a história de São Raimundo Nonato-PI. Univasf, São Raimundo Nonato, 257-286.

Aquino, K.P.N.; Santos, R.S. 2014. Cemitério Nossa Senhora de Lourdes: lugar de memória da cidade de São Raimundo Nonato-PI. In: Kestering, C. (Org.). Anais Escavando história: São Raimundo Nonato além dos cem anos: III exposição II ciclo de palestras. Univasf, São Raimundo Nonato, 2014, 36-46.

Arraes, E. 2014. Entre reses e almas: questões sobre urbanização, arquitetura e arte das missões jesuíticas dos sertões das capitanias do Norte. Pós 21: 84-100.

Brazon, M. 2012. Aproximação a historiografia da arquitetura colonial brasileira as ideias de John Bury. Da Pesquisa 7: 190-205.

Bury, J. 2006. Arquitetura e arte no Brasil Colonial. Iphan: Monumenta, Brasília.
Carvalho, M.A. et al. 2016. 140 anos de um patrimônio edificado: Igreja Catedral de São Raimundo Nonato - Piauí (1874-1876). In: Kestering, C. (Org.). Anais Escavando história: São Raimundo Nonato além dos cem anos: $V$ exposição IV ciclo de palestras. Univasf, São Raimundo Nonato, 81-87.

Cavalcante, F.J.P. 2008. Pe. Henrique José Cavalcante: o mestre da caridade. Petrolina, [s. n.].

Cavalcanti Filho, I. 2013. Documentando a arquitetura religiosa no Brasil colonial: a linguagem expressa na iconografia azulejar dos conventos franciscanos no Nordeste. In: Anais do $3^{\circ}$ Seminário ibero-americano: Arquitetura e documentação, 2013, Belo Horizonte.

Costa, L. 1952. Arquitetura brasileira. Ministério da Educação e Saúde, Rio de Janeiro.

Costa, L. 2010. A arquitetura dos jesuítas no Brasil. ARS 8: 127-195.

Cruz: suas formas e significados. 2018. Disponível em: <https://bit.ly/30cJJht> Acesso em: 10/08/2018.

Dias, W.P. 2001. São Raimundo Nonato: de distrito freguesia a vila. Teresina, [s.n.].

Gomes, J.N. 2015. As festividades do padroeiro em São Raimundo Nonato-Piauí (2000-2014). Trabalho 
Igreja Matriz de São Raimundo Nonato/PI: uma análise a partir da arqueologia da arquitetura

R. Museu Arq. Etn., 34: 72-86, 2020.

de conclusão de curso. Universidade Estadual do Piauí, São Raimundo Nonato.

Instituto Brasileiro de Geografia e Estatística. 2017. Pilão Arcado - História \& Fotos. Disponível em: $<$ https://bit.ly/33gITlE > . Acesso em: 10/09/2019.

Instituto Oswaldo Cruz. 2019. Expedições cientificas do Instituto Oswaldo Cruz ao Nordeste do Brasil - Parte I. Disponível em: <https://bit. ly/2CTGAdS> acesso em: 01/09/2019.

Kestering, C. (Org.). 2013. Escavando a história de São Raimundo Nonato-P $i$. Univasf, Petrolina.

Loewen, A.B. 2011. Estilo desornamentado, arquitetura-chã: alguns aspectos do renascimento na Península Ibérica. Pós 18: 56-69.

Mayer, V.F. 2003. Aspectos gerais da arquitetura religiosa colonial baiana. Arqtexto 3: 144-153. Disponível em: <https://bit.ly/2CUMj37>. Acesso em: 30/07/2018.

Najjar, R. 2002. Manual de arqueologia histórica em projetos de restauração. Iphan, Rio de Janeiro. Disponível em: <https://bit.ly/30ekFGM $>$. Acesso em: 10/03/2018.

Najjar, R. 2011. Para além dos cacos: a Arqueologia Histórica a partir de três superartefatos (estudo de caso de três igrejas jesuíticas). Boletim do Museu Paraense Emilio Goeldi. Ciências Humanas 6: 71-91.

Pereira, S.G. 2005. A historiografia da arquitetura brasileira no século XIX e os conceitos de estilo e tipologia. Estudos Ibero-Americanos 31: 143-154.

Piauí. Fundação Cultural do Piauí. Coordenação de registro e conservação. 2012. Cadastro das edificações de valor histórico e arquitetônico de São Raimundo Nonato-PI. Fundac, Teresina.
Pinheiro, M.L.B. 2013. Repercussão das ideias de Ricardo Severo e Raulino no debate arquitetônico dos anos de 1920 no Brasil. In: Fernandes, J.M.; Pinheiro, M.L.B. (Coords.). Portugal, Brasil, África: urbanismo e arquitetura - do ecletismo ao modernismo. Caleidoscópio, Casal de Cambra, 47-67.

Pires, T.A.P. 2008. Padre Antônio Joaquim Gomes. Casa da Memória, Jaguariúna. Disponível em: $<$ https://bit.ly/30dso8j>. Acesso em: 01/09/2019.

Rio de Janeiro. Secretaria Municipal de Urbanismo. Centro de Arquitetura e Urbanismo. 2000. Guia de arquitetura colonial, neoclássica e romântica do Rio de Janeiro. Centro de Arquitetura e Urbanismo, Rio de Janeiro.

Senos, N. 2012. A arquitectura portuguesa chã antes e depois de George Kubler. Revista Tritão 1: 1-21.

Silva, L.; Rocha, M.; Melo, N.B.A.L. 2015. A arquitetura dos templos católicos erguidos no sítio histórico de Teresina entre meados e final do século XIX. Anais do VII Mestre e Conselheiros. Agentes multiplicadores do Patrimônio"Patrimônio e cidades", 2015, Belo Horizonte.

Smith, R.C. 2012. Robert Smith e o Brasil: arquitetura e urbanismo. Iphan, Brasília.

Teles, A.C.S. 2014. Brasil: arquitetura religiosa barroca. Iphan, Brasília. Disponível em: <https://bit. ly/2EqoReb>. Acesso em: 30/07/2018.

Toledo, B.L. 2012. Esplendor do barroco luso-brasileiro. Ateliê Editorial, São Paulo.

Zarankin, A. 2001. Paredes que domesticam: arqueologia da arquitetura escolar capitalista: o caso de Buenos Aires. Tese de Doutorado. Universidade Estadual de Campinas, Campinas. 